\title{
Determinants of uptake and strategies to improve agricultural insurance in Africa: a review
}

\author{
Emmanuel Nshakira-Rukundo, ${ }^{1,2,3 *}$ (D) Juliet Wanjiku Kamau, ${ }^{4}$ and Heike Baumüller ${ }^{2}$ \\ ${ }^{1}$ Institute for Food and Resource Economics (ILR), University of Bonn, Bonn, Germany; ${ }^{2}$ Center for \\ Development Research (ZEF-B), University of Bonn, Bonn, Germany; ${ }^{3}$ Apata Insights, Kampala, Uganda \\ and ${ }^{4}$ Professorship for Organic Farming with a focus on Sustainable Land Use, Justus Liebig University \\ Giessen, Giessen, Germany \\ *Corresponding author. E-mail: erukundo@uni-bonn.de
}

(Submitted 11 August 2019; revised 29 May 2020, 22 October 2020; accepted 13 January 2021; first published online 12 April 2021)

\begin{abstract}
Weather shocks affect smallholder farmers and pastoralists in Sub-Saharan Africa unequally. Agricultural insurance has emerged as a safety net option to protect farmers' welfare. However, in comparison to other regions, fewer African farmers and pastoralists have adopted agricultural insurance. This review synthesises broad recent literature on why insurance take-up has remained low and highlights six key themes, including: (1) product quality, (2) product design, (3) affordability, (4) information and education, (5) behavioural and sociocultural factors, and (6) the role of government in enabling markets. We shed light on how insurance uptake can be encouraged.
\end{abstract}

Keywords: agricultural insurance; Africa; take-up

JEL classification: D52; G22; O13

\section{Introduction}

Smallholder farmers face myriads of climate hazards and agricultural insurance has increasingly been promoted to provide protection (Hellmuth et al., 2009). However, take-up of agricultural insurance in Sub-Saharan Africa remains the lowest (Hess and Hazell, 2016). Instead, smallholder farmers continue to rely on less effective mechanisms such as asset depletion (Börner et al., 2015; Yilma et al., 2017) or dependency on livestock (McPeak and Doss, 2006; Ng'ang'a et al., 2016) and savings even when insurance options are available (Delavallade et al., 2015). Agricultural insurance remains unpopular, unattractive and poorly demanded by a majority of farmers in low- and middle-income countries (Binswanger-Mkhize, 2012). This is despite the evidence of its potential in improving farmers' and pastoralists' livelihoods, unlocking investments in production and eventual poverty reduction. In this review paper, we explore why takeup has remained low and what strategies might be employed to spur its take-up among farmers and pastoralists in Africa. 
Table 1. Agricultural insurance coverage in smallholder farmers across developing and middle-income countries

\begin{tabular}{lccc}
\hline & Latin America \& Caribbean & Asia & Africa \\
\hline No of small farms & $21,005,083$ & $420,078,903$ & $59,056,107$ \\
\hline No of insurance policies & $3,315,626$ & $194,185,463$ & 600,975 \\
\hline$\%$ of insured smallholder farmers & $15.8 \%$ & $46.2 \%$ & $1.0 \%$ \\
\hline Current coverage & & $2,039,506$ \\
\hline$\%$ of farmer currently insured & & $3.5 \%$ \\
\hline
\end{tabular}

Sources: Number of farms (Lowder et al., 2016) - data does not include Somalia, Sudan, Eritrea, Mauritius and Burundi, Number of insurance policies (Hess and Hazell, 2016), Current coverage - authors' estimates from several sources (see online appendix table A1).

This review supplements other recent reviews (Marr et al., 2016; Smith, 2016; Carter et al., 2017; Jensen and Barrett, 2017; Platteau et al., 2017; Yuzva et al., 2018; Ali et al., 2020b) but also makes important contributions that other reviews have not addressed. First, the review exclusively focuses on Sub-Saharan Africa (SSA) due to its higher vulnerability to weather shocks than other regions (Coe and Stern, 2011). In the region, droughts between 1980 and 2013 are said to have affected more than 360 million people and caused more than US\$31 billion in losses (FAO, 2015). The 2008-2011 drought in Kenya alone led to US\$11 billion in losses (FAO, 2015) and the 2016 drought in Malawi dented the country's economy by US $\$ 400$ million (Reeves, 2017). The trend of losses is not likely to decrease (Haile et al., 2020a; Spinoni et al., 2020). Despite these losses, insurance take-up remains the lowest in the world. Accordingly, of the 51 million smallholder farmers in Africa (Lowder et al., 2016), ${ }^{1}$ only about 1.3 per cent have agricultural insurance (Hess and Hazell, 2016). Our more updated estimate suggests current take-up around 3.5 per cent but this remains far below rates in Asia and Latin America (table 1). The low insurance coverage situation in SSA therefore raises questions possibly specific to the region and requires closer assessment.

This review further broadens the focus on various issues that previous reviews did not cover. For instance, Platteau et al. (2017) assessed demand for micro-insurance, which is technically different from agricultural insurance. Marr et al. (2016), Carter et al. (2017) and Jensen and Barrett (2017) specifically focused on index insurance only, which is only one of the several agricultural insurance types (Iturrioz, 2009). Yuzva et al. (2018) assessed the effect of basis risk and did not refer to many other challenges farmers might face in their take-up decisions. The reviews by Smith (2016) and Ali et al. (2020b) are the closest to our study in consideration of a wide range of issues covered. A critical addition to these is the diversion from the 'expert review' methodology to one that provides more details on the process of literature search as well as inclusion/exclusion decisions. None of the existing reviews precisely covers Africa.

By condensing broad qualitative and quantitative literature, and taking an integrativestyle review (Pautasso, 2013), we expound on issues hindering the take-up of agricultural insurance, clustered in six key themes. These are: (1) product quality, (2) product and contract design, (3) income and affordability, (4) information, knowledge and education

\footnotetext{
${ }^{1}$ The data does not include Somalia, Sudan, Eritrea, Mauritius and Burundi.
} 
reasons, (5) behavioural and socio-cultural factors, and finally (6) the role of governments in policy setting, regulation and market stabilisation. These six themes all cut across demand and supply. From the demand side, there is an insufficient purchase of agricultural insurance products by farmers - partly because of budget limitations and because of the low knowledge of and about insurance. We elaborate on how demand can be spurred by providing demand subsidies, which relax farmer budgets and increase affordability. From the supply side, farmers require the products not only to be available but also to be of good quality since poor quality products are likely to leave farmers in worse off situations (Clarke, 2016). We not only explore how suppliers can be enabled to provide more insurance but also how to increase the quality of existing products. Moreover, while insurance remains voluntary, governments and related institutions can spur markets not only through infrastructure and meso-level services such as reinsurance, but also by setting up enabling policies and regulatory institutions that build confidence. Through enabling innovation and setting quality standards, governments can avoid low product equilibria (Clarke and Wren-Lewis, 2013). These factors are not singular recommendations of dos and don'ts. Indeed, as figure A1 (in the online appendix) shows, they are interconnected and should be adjudged in the broader ecosystem.

The rest of this paper is organised as follows. In section 2, we provide a brief historical and current status of agricultural insurance in Africa. Section 3 gives our review methodology and literature search strategy elaborating on the inclusion and exclusion strategy. In section 4 , we detail the results of this review, and make a short conclusion in section 5 .

\section{Agricultural insurance in Africa: an overview}

Agricultural insurance has been present in some African countries since the early 20th century (Burger, 1939; Adesimi and Alli, 1980; Alli, 1980; Atlas Magazine, 2017), however, the market remains very small. As of 2008 , four out of 47 countries in the region had a functioning agricultural insurance program and an additional six were implementing pilot projects (Mahul and Stutley, 2010). The last decade has observed gradual improvement ranging from agriculture micro-insurance (Di Marcantonio and Kayitakire, 2017) with several countries piloting index insurance (Sandmark et al., 2013). Hess and Hazell (2016) found that about 653,000 farmers had some form of insurance coverage and our updated program coverage suggests over 2 million smallholder farmers have insurance in Africa (see table A1, online appendix). At the continental level, the African Risk Capacity (ARC), set up in 2012, has facilitated the entry of countries into regional risk pools (Vincent et al., 2018). Currently, the ARC comprises 34 member states of which 11 took part in the 2019-2020 risk pool (see table A2, online appendix). While countries' participation has increased, there is a need for more political support. In 2016, both Kenya and Malawi dropped out of the risk pool due to internal politics and have not been able to re-join ever since (Hohl, 2019). Moreover, for the risk pool to be more effective, more countries need to enrol. In general, while agricultural insurance in Africa has grown, coverage is still very small especially in comparison to other regions and the number of smallholder farmers and pastoralists in the region. While several countries have started pilot programmes and a few like Zambia are scaling up, climate shocks tend to be crosscountry and covariate in nature; hence the necessity for regional and continental risk pools remains critical. 


\section{Literature search methodology}

We searched literature from Scopus and Web of Science covering the period up to September 2020. In the online appendix, we provide a detailed search process showing all variations of search terms used. In addition, we included grey literature from organisations known to work on agricultural insurance. These were the World Bank, the International Fund for Agriculture and Development, the International Food Policy Research Institute, the United Nations Institute for Environment and Human Security, and the Feed the Future Innovation Lab for Markets, Risk and Resilience of the University of California, Davis. All our literature is in English. We included both qualitative and quantitative studies.

Starting with 687 documents, we selected 120 documents for final full-text review. The literature selected included qualitative, quantitative empirical studies as well as simulation studies. The majority of the literature (80/120 papers) was from the period 2016-2020, further underlining our effort to cover the most recent evidence. The studies reviewed were from 23 countries across the continent with 58 per cent from Ethiopia and Kenya, mainly from the evaluations of the Index-Based Livestock Insurance programmes. Whereas Zambia had the highest insurance coverage, only three studies were from the country. Figure 1 shows the distribution of the studies reviewed by country. Details of the inclusion criteria, studies reviewed by their research methodology, as well as the summary of their time coverage can be found in online appendix figures A1-A3, respectively.

\section{Results}

\subsection{Product quality}

Agricultural insurance has come under scrutiny on how valuable it is to smallholder farmers in developing countries (Binswanger-Mkhize, 2012). A key concern is that insurance products are often of poor quality and their acquisition can lead to worse outcomes than without them (Clarke, 2016). One aspect of poor product quality is the level of basis risk, which refers to the probability that insurance does not cover an insurance-holding farmer when they experience the insured shock because the level of the insurance threshold (often an index) is imperfectly correlated with losses incurred. Both simulations (Elabed et al., 2013) and empirical studies (Hill et al., 2013; Jensen et al., 2018, 2019) have shown that when basis risk is higher, farmers are less likely to purchase insurance. There are three categories of basis risk. The first is the geographical/spatial basis risk (Jensen et al., 2018), which measures the distance from a farmer's plot to the measurement point. The second is design basis risk which emanates from the models and variables used to construct an index (Elabed et al., 2013; Jensen et al., 2019). The third is temporal basis risk which is related to the timeframe in which the index is measured (Díaz Nieto et al., 2010). Simulation studies in Cameroon and Niger have indicated that basis risk might be as high as 50 per cent in most indices (Leblois et al., 2014a, 2014b), implying that there is a 50 per cent chance that an insured farmer's risk might not be covered by their insurance due to such poor correlation. To this farmer, purchasing insurance with substantial basis risk might not only introduce a loss of income (in paid premiums) but also leave her in a worse off situation since it also limits her alternative options (Barré et al., 2016; Clarke, 2016; Jensen et al., 2016). To providers, there are reputation risks to contend with (Morsink et al., 2016; Reeves, 2017) further limiting their future market. Spatial basis risk is the most pronounced of the three categories. For instance, in some studies, increasing 


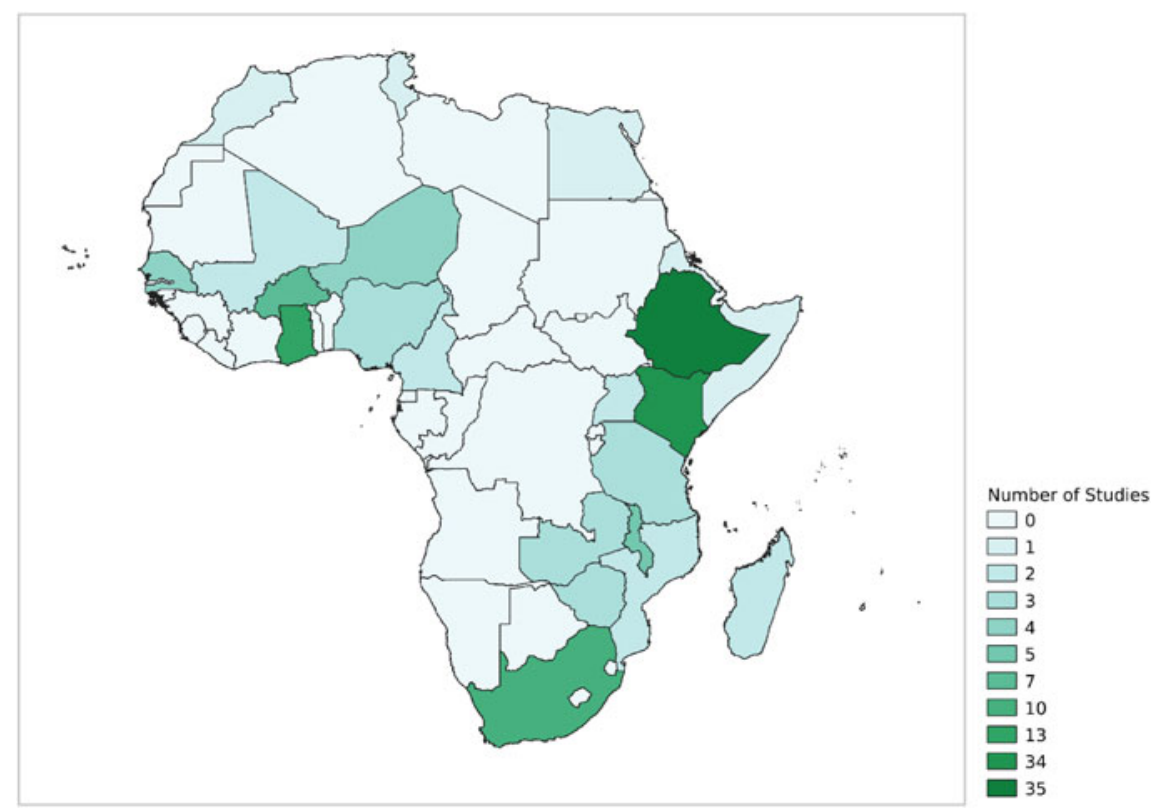

Figure 1 . Coverage of studies reviewed by country.

Source: Authors.

distance from the farmer's plot to the weather station reduced demand by up to 20 per cent (Hill et al., 2013; Amare et al., 2019). Spatial basis risk is also linked to adverse selection, where some farmers might know local agro-climatic and agro-ecological conditions likely to affect the cropping or livestock outcomes, which may be unknown to the insurance provider. Jensen et al. (2018) found that households in locations that had higher average losses and those in locations that had less basis risk had higher insurance demand than the rest. The reverse can also hold, that households not enrolling in insurance are also aware of their disadvantageous locations. Moreover, it is not just the presence of basis risk but also the perception of its presence that influences farmers (Castellani, 2015; Chantarat et al., 2017). These perceptions might be shaped by local geographies, which might not be considered during the construction of the index insurance product. Basis risk might also arise from random idiosyncratic shocks due to random variation in, for instance, rainfall. Evidence from northern Kenya showed the existence of these idiosyncratic shocks in villages covered by insurance which, even after insurance coverage, left insurance holders with 69 per cent of their original risk exposure due to basis risk (Jensen et al., 2016).

Basis risk can be reduced through several strategies. First, Morsink et al. (2016) suggest that products can cover all possible losses related to the peril which the insurance product covers as opposed to a single dimension of losses. They call this strategy insured peril basis risk. Secondly, insurance might cover losses from agricultural production that might not be caused by the insured peril (production smoothing basis risk). To capture the entirety of insured peril basis risk, insurance product development might consider using multiple sources and types of data to better explain both the production risk and multiple dimensions of possible losses (Wang et al., 2013). While indices have always 
been constructed by single variables such as remotely sensed vegetation or rainfall or temperature data (Hochrainer-Stigler et al., 2014; Vrieling et al., 2014; De Oto et al., 2019), more recently, new variables such as soil moisture have shown promise in indices (Enenkel et al., 2017, 2019; Von Negenborn et al., 2018). Comparing index insurance based on a rainfall index and an evapotranspiration index, Von Negenborn et al. (2018) found that the rainfall-based index underestimates the effect of weather on the risk of repaying agricultural credit, especially during harvest months. The evapotranspirationbased index was, on the other, hand more precise in accounting for the spikes in weather on credit risk. Rainfall-based weather insurance had more basis risk than the evapotranspiration-based index. Enenkel et al. (2017) assessed the benefit of using soil moisture data and found that it had a higher agreement with vegetation anomalies than conventional rainfall data, implying that soil moisture data has the potential of reducing basis risk. However, it is important for insurance providers to consider both precision and time lags. Depending on the indices used, some products are likely to be more asset replacing while others are more asset protecting (Jensen et al., 2019). Some suitable products might be more costly while more precise (low basis risk) products might have more time lags and delays to trigger. Timeliness of products might depend on the amount of monitoring for which costs can be prohibitive to providers. More recently, picture-based crop monitoring offers promise. First tested and implemented in India (Ceballos et al., 2019; Hufkens et al., 2019), it is currently being tested in Ethiopia (Porter et al., 2020) and Kenya (ACRE Africa, 2020). Picture-based monitoring reduces the costs of monitoring while leveraging farmer participation and increasing their motivation and still providing real-time evidence of crop health to assess losses and triggering pay-outs.

These innovations, while promising, have drawbacks and should be carefully considered. For instance, remotely sensed data collection for variables such as evapotranspiration or soil moisture, is expensive in acquisition and processing (Coleman et al., 2017). Secondly, the success of these innovations depends on the level of technology diffusion in rural SSA. For instance, while picture-based insurance contracts are based on farmers' access to smartphones and the internet, overall internet adoption in Ethiopia is only per cent, according to the World Bank's World Development Indicators, and most likely much lower in rural communities. Moreover, low internet adoption and high internet costs introduce additional costs to farmers, which might wade off prospective demand. Technologies based on such platforms might therefore struggle to be adopted.

\subsection{Product and contract design}

A second major reason hampering agricultural insurance take-up in Africa is product design. By product design, we imply four main issues: (1) the spatial or geographic scale of coverage, (2) product item coverage, (3) timing of index triggers, and (4) insurance provided alongside other services (bundling).

\subsubsection{Spatial coverage of insurance policies}

Conventional insurance products are single-scale products with one trigger set at a certain spatial scale (Elabed et al., 2013). For these, basis risk arises from both the random or systematic idiosyncratic risk as well as the design risk at the spatial scale of coverage. Because of higher basis risk from such contracts, farmers are less likely to purchase such insurance, especially those with more local agro-ecological information than insurance providers (Jensen et al., 2018). Accordingly, design risk can be reduced by implementing multiple-trigger contracts where the index is not assessed on one scale 
but rather on more than one scale (Elabed et al., 2013). In an experiment with Malian cotton farmers, Elabed et al. (2013) found that demand for a two-trigger or two-scale insurance contract was about 40 per cent higher than the conventional single trigger contract. They found that the multi-scale insurance contract reduced both false negatives, where an individual whose yield was below the average and he/she did not receive insurance payout (basis risk), and false positives, where an individual whose yield was above the average still received an insurance payout. One example of a multi-scale insurance product is an area-yield insurance product in Tanzania that introduces a conditional audit (Flatnes et al., 2018). The authors compared a satellite-based index insurance contract and another contract that incorporated an audit requested by farmers if basis risk reached a certain threshold. Flatnes et al. (2018) found that willingness to pay an auditincorporated contract was 64 per cent higher than the non-audit contract. This implies that a reduction in basis risk from better measurement and allowing farmer grievance management increases trust in products and demand.

\subsubsection{Product item coverage profile}

The product item coverage profile is another dimension of product design. Here, we imply a basic assessment of how many perils and how many crops the insurance product covers. Conventional insurance products cover a specific crop that is faced with one particular peril. However, farmers are not only faced with various covariate and idiosyncratic shocks but also grow multiple crops in a single growing season. Crop specific insurance products might, therefore, not be appropriate for such farmers. For instance, Berg et al. (2009), using simulated insurance contracts based on 20 years of production across five crops, found that farmers cropping maize and groundnuts were more protected compared to those growing millet, sorghum or cotton. Siebert (2016) showed the necessity of using two different indices to cover millet and rice across similar climatic regions because of the negative correlation in the shocks affecting both crops. Therefore, in such cases where the incentives for the provision of single index-based insurance products are not conducive, providers might devise multi-crop and multi-peril insurance products with one or two 'leading' crops and additional 'secondary crops'. Recent evidence shows farmers value multi-crop, multi-peril insurance products highly (Bulte et al., 2019) though there is need for more research to assess the willingness to pay for such products versus the common single crop, single peril insurance products.

\subsubsection{Trigger period}

The other dimension of product design is the time of the trigger. For any kind of insurance, coverage happens at the onset of a shock, i.e., when an individual falls sick - for health insurance; when an automotive accident happens - for motor insurance; or when one losses employment - for employment insurance; and so forth. Basic agricultural insurance operates along similar lines: payoff occurs after the shock has been experienced. However, the difference between agricultural insurance is that shocks can be predicted with more confidence than with other kinds of insurance. When the possibility of shocks is known, what matters more is if the insurance can prevent the effects of the shock and if it can provide the insured with other options of production and consumption smoothing. Farmers and livestock owners are, therefore, likely to demand insurance based on how much it provides this protection.

Recent evidence suggests that insurance participation reduced herd offtake behaviour (selling of livestock) as pastoralists were less fearful and more confident that losses would 
be covered (Gebrekidan et al., 2019). However, the prevention of losses is more important than the losses being covered. This is, therefore, a matter of how much loss insurance covers and how frequent the payments can be made to allow farmers to exercise protective options. Karlan et al. (2014) suggested that experimenting with small losses and higher frequency payouts could improve demand. Norton et al. (2014) showed that farmers preferred high-frequency insurance when such products were on offer. By pointing at the benefits such as insuring high probability-small loss events (which are usually selfinsured), farmers might find such products attractive (Norton et al., 2014). In addition to the frequency of payouts, their timing also matters. Optimising remote sensing data for instance and providing earlier payouts could allow vulnerable farmers to utilise mitigation strategies such as alternative forage sources for livestock (Vrieling et al., 2016) or access to food to prevent farmers from falling below the minimum food requirements (Hochrainer-Stigler et al., 2014). Vrieling et al. (2016) showed that payouts made between one to three months before the onset of the drought would give farmers more time to optimise protective alternatives.

Jensen et al. (2019) also showed that the insurance product with a one-month early payment supported 91 per cent of the pastoralists compared to one with a one-month late payment, which was helpful to only 68 per cent of the households. However, such early-payment policies might have higher unaffordable premiums as Jensen et al. (2019) further showed. In their study, the early-payment contract product would cover only 46 per cent of households if the premium loading were 50 per cent and almost none of the households if the loading were 100 per cent. Moreover, insurance products with highfrequency payments also increase provider transaction costs. Therefore, it is important to consider the desire for more attractive products alongside their related costs.

\subsubsection{Bundling insurance with other services}

Agricultural insurance can be combined with other products or services. Carter et al. (2016) made a theoretical case for combining insurance with other services such as credit (often referred to as bundling), suggesting it as one of the ways to make insurance popular. Insurance can be combined with credit services (Giné and Yang, 2009; Meyer et al., 2018; Ahmed et al., 2020) or inputs such as drought-tolerant seeds, high yielding seeds or fertilisers (Leblois et al., 2014b; Lybbert and Carter, 2015; Awondo et al., 2020; Visser et al., 2020). The basic idea is that farmers might be more enticed to purchase insurance if they get more services through one contract. It is also easier for providers to deliver multiple services without increasing their administrative and transaction costs, thereby lowering the unit costs for a single product. Another attraction to bundling insurance with credit is that farmers would generally pay insurance premiums off their credit and therefore do not have to pay cash up front, hence relaxing their budget stress. Karlan et al. (2014) showed that after removing credit constraints by providing a cash grant, insurance demand increased by $40-50$ per cent in Ghana. Programmes delivering insurance by bundling it with other services seem to be the ones able to achieve some scale. The Zambia Farmer Input Support Programme offers an example of bundling insurance with inputs. Under this programme, farmers pay premiums when receiving inputs from a government programme. In case of triggers, the insurance companies (through the Ministry of Agriculture) pay farmers through e-vouchers to secure inputs for a new cropping season. The programme covered more than 900,000 farmers in the 2017/18 Zambian financial year (World Bank, 2019). Similarly, the second largest insurance programme in the region, ACRE Africa, currently providing coverage to over 313,000 farmers, works 
with input service providers under One Acre Fund, a farm inputs and credit providing organisation (Hess and Hazell, 2016).

There are, however, certain caveats to bundling insurance with other services. The first is that farmers generally prefer to have freedom in deciding which products and services to purchase and not to be forced to take products that they do not want, and products that might be inadequate for them later. In one of the major studies on agricultural insurance in SSA, Giné and Yang (2009) found that farmers who were offered loans with insurance for high yielding groundnuts had a 13 percentage point lower insurance demand compared to those with simple credit without insurance. Unlocking credit constraints alone increased demand for insurance while packaging credit with insurance might have given farmers fewer choices. Gallenstein et al. (2019) arrived at a closely similar conclusion through a willingness to pay experiment in Ghana. They found that compelling farmers to purchase index insurance as they took out an agricultural loan generally lowered loan demand because it generally increased the cost of the loan when the insurance premium was included. Loan demand was 75 per cent compared to 54 per cent for a loan with insurance. Finally, regarding bundling with other technologies such as high yielding or drought-tolerant seeds, farmers need to have a good understanding of these technologies available as they might have different levels of benefits. Testing bundling across 19 improved maize varieties with insurance in 49 locations in Eastern and Southern Africa, Awondo et al. (2020) found a high variation in the performance of different combinations such that farmers were highly likely to select a sub-optimal combination. Awondo et al. (2020)'s simulations indicate that bundling has to be a very precise activity across regions with both providers and farmers choosing the best combination of systematic bundling, especially where more than one product is available. It is, therefore, important that bundling be considered carefully, as it might not solve all challenges.

\subsection{Income and affordability}

A major challenge with bolstering demand for agricultural insurance is farmers' budget constraints. The prospective market for insurance is therefore divided into those with higher incomes demanding more insurance and those with lower incomes who cannot afford it (Hill et al., 2013; Karlan et al., 2014; Bogale, 2015; Takahashi et al., 2016; Tadesse et al., 2017; Bishu et al., 2018; Fonta et al., 2018; Janzen and Carter, 2019). Moreover, weather shocks in previous periods reduce farmers' future income and demand. Conventionally, as farmers' incomes improve, so does their demand for insurance. Agriculture income is, in particular, predictive of insurance demand (Takahashi et al., 2016; Abugri et al., 2017; Bageant and Barrett, 2017). However, as households' incomes improve, so does the likelihood to move out of agriculture and therefore income diversification tends to dampen demand (Bogale, 2015). To increase demand, we highlight two avenues below that might increase demand through income-based interventions.

\subsubsection{Demand subsidies}

Demand can be induced through discounts and demand subsidies (Mcintosh et al., 2013; Giné et al., 2014; Karlan et al., 2014; Tadesse et al., 2017; Bulte et al., 2019; Janzen and Carter, 2019; Matsuda et al., 2019; Ahmed et al., 2020; Stoeffler et al., 2020). A third party such as the government would then pay the remainder of the premium. Moreover, discounts and subsidies might work in favour of politicians who make policy (Hazell et al., 2017). Also, subsidies might lower the costs of insurance and overall costs of 
social protection as households participate in its financing (Janzen et al., 2020). Recipient households contribute to social protection financing but also reduce their future social protection needs if they are more protected.

However, two crucial issues remain of concern regarding demand subsidies. The first concerns the sustainability of subsidies and the eventual demand when subsidies end. There is limited evidence on this but one study in Ethiopia provides some useful information. Takahashi et al. (2016) found that demand was not affected when subsidies ended. They found that households that purchased insurance after receiving a discount voucher in the first year did not change their demand behaviour in the subsequent year when discounts were lifted, as learning effects after purchasing insurance dominated price anchoring effects. The second issue is whether subsidies are the best use of public resources in comparison to alternative social protection mechanisms such as cash transfers or input support. With limited resources, policymakers have to choose the most effective instruments. Evidence on which instruments have better returns for farmers is mixed. In a simulation study, Ricome et al. (2017) compared insurance subsidies with reducing the cost of credit, subsidising fertilisers or offering cash transfers. They found that insurance subsidies brought the least utility and lowest certainty equivalent income in smallholder groundnut farmers in Senegal in comparison to any kind of credit, fertilisers or cash transfers. In an assessment of farmer preferences, Marenya et al. (2014) found that Malawian smallholder farmers reduced demand for crop index insurance when they were offered a slightly higher cash benefit, showing a preference for cash transfers. Mahul and Stutley (2010) also warned that premium subsidies might be inefficient and increasingly expensive for governments, especially given that once started, it is not easy to roll them back.

However, simply choosing between cash and insurance might reveal immediacy biases rather than effective long-term protection and poverty reduction potential (Delavallade et al., 2015). The evidence indicates that while farmers might prefer cash, agricultural insurance provides better opportunities for long-term poverty reduction and disaster management. In a simulation study, Carter and Janzen (2018) showed that enabling farmers to be insured dominated other social protection instruments such as cash transfers. By testing a multi-generational household model of consumption, accumulation and risk management, they found that a 50 per cent increase in premium subsidies propped up insurance and slowed both the poverty rate and poverty depth, leading to a 20 per cent increase in GDP growth. Jensen et al. $(2017 a, 2007 b)$ also found that subsidy-supported insurance was overall more poverty averting compared to cash transfers. While cash transfers improved short-term health measures, insurance increased investments in productive assets, reduced livestock sales and increased adultequivalent income (Jensen et al., 2017a, 2017b). Finally, Janzen et al. (2020), in another simulation study spanning over 50 years of data in Kenya and Ethiopia, showed that insurance not only had higher vulnerability reduction potential but also brought additional investment incentive potential. They found that with insurance, farmers could contribute to their social protection, hence reducing the overall costs of protection and reaching wider coverage. The study further revealed that without insurance, asset poverty increased by 50 per cent while with insurance it decreased by 42 per cent. A further 10 per cent of poverty reduction came from unlocking resources for farm investments. These studies show that higher adoption of agricultural insurance can help economies move from reactive social protection policies to more proactive policies and hence achieve more poverty reduction. 
However, some insurance types, such as livestock insurance, seem to protect a section of households that are better off (Chantarat et al., 2017; Ricome et al., 2017; Janzen and Carter, 2019). Chantarat et al. (2017) and Janzen and Carter (2019) showed that effective coverage for livestock index insurance was between 10 and 15 total livestock units. The majority of rural households do not have as much livestock as these thresholds suggest. There is, therefore, room for other social protection instruments for various sub-groups. As Janzen et al. (2016) showed, poorer households receiving cash transfers retained and accumulated assets faster, while non-poor households with insurance protected and invested in their livestock more. Governments and insurance providers, therefore, need to think more about equity (Fisher et al., 2019) and consider insurance alongside other instruments so that insurance does not breed inequality.

\subsubsection{Flexible payment mechanisms}

Alternatively, insurance providers can offer flexible premium payment mechanisms, which relax budget limitations without affecting premiums. We highlight two of these, namely: (1) flexible time of payment, and (2) labour-based payments. In conventional insurance of all kinds, premiums are paid before coverage begins. For rural farming households, agricultural insurance premiums would have to be paid before the cropping season. However, at such times, smallholder farmers' budgets are limited due to other necessary expenditures such as farm inputs and extension services. Insurance ends up being at the bottom of their priorities list (Binswanger-Mkhize, 2012). One avenue of easing farmer budgets is by making flexible the time of payment. Casaburi and Willis (2018) tested a pay-at-harvest insurance product with smallholder sugarcane contract growers in Kenya. In their experiment, they found first that farmers demanded less insurance at the beginning of the season, not due to liquidity challenges but because paying upfront was not marginal appropriate for their expected return. Secondly, when farmers had the option of paying premiums after harvest, demand increased from 5 per cent in the pay-up-front option to 72 per cent in pay-at-harvest option. In a related study in Ethiopia, Belissa et al. (2019) found that when farmers had a pay-at-harvest option, demand increased from 8 per cent to 24 per cent. However, the main challenge with pay-at-harvest insurance products might be contract enforcement as default rates might be high. Contract enforcement might not have been an issue in the Casaburi and Willis (2018) study because they worked with contract farmers. These do not represent the average rural farmer. It is therefore essential for providers to consider default and contract enforcement for average smallholders.

Another budget relaxing payment mechanism is labour-based payments linked with other social protection programmes (Tadesse et al., 2017; Vasilaky et al., 2019). An integral component of such social protection programmes is public works, where individuals are paid for a specific number of public works. Two studies evaluated the possibility of farmers paying premiums with their labour. Tadesse et al. (2017) conducted a willingness to pay for agricultural insurance in Ethiopia and found that individuals were more willing to work in return for insurance, even at lower daily wage equivalents than the conventional cash-for-work programmes. They find that 60 per cent of the farmers would pay insurance using their labour. In another study, Vasilaky et al. (2019) used experimental games and offered real commercial insurance after the game. First, they find that participating in the Productive Safety-Net Programme (PSNP) increased insurance purchase by up to 19 percentage points. They then compared between cashpaying and labour-paying sub-samples. They found that while the effect of experimental games on purchasing insurance with cash increased insurance purchases by 10 per cent, 
it increased purchases by 17 per cent in households that paid insurance with labour. They further found that total insurance purchased was higher for labour-paying households compared to cash-paying households. From these two studies in Ethiopia, it seems convincing that linking agricultural insurance with other social protection programmes, in particular public works programmes, could achieve higher gains in encouraging more rural households to purchase insurance. However, the complementarity of insurance and other social protection mechanisms is not always guaranteed. Households enrolled in other social protection programmes might demand insurance less if they consider that current programmes provide sufficient insurance (Duru, 2016).

Finally, there is the role of Information and Communications Technologies (ICTs) in enabling farmers to utilise payment platforms. Insurance companies are often thin on the ground and not able to reach most locations where farmers are located. Moreover, agricultural factor markets in SSA are grossly lacking in that most services are urban biased (Dillon and Barrett, 2017; Allen IV, 2018). Lack of well-functioning agricultural factor markets makes distribution expensive and prohibitive. However, ICTs help to bridge the gap of financial intermediation between suppliers and consumers by providing the last mile payment service. In other types of insurance such as health insurance, utilising the opportunities of mobile payment systems has enabled massive enrolment through mobile-based insurance payments (Wasunna and Frydrych, 2017). However, agricultural insurance is still lagging. Of the 31 million mobile-based insurance policies worldwide that were issued by June 2015, only 7 per cent were for agricultural insurance (GSMA, 2015). However, some opportunities will require full leveraging. For instance, all insurance policies by ACRE Africa in Kenya, Tanzania and Rwanda are provided over mobile-based payment services. Other smaller initiatives have been registered in several countries, and mobile payment could provide options to suppliers. However, the cost of internet services and mobile-based payment service taxes and costs remain high in many countries. Removing or decreasing some of the costs of using these platforms might make it simpler for rural farmers to adopt such technologies.

\subsection{Education, knowledge and information}

Most rural farmers are not only illiterate but also unaware of new technologies such as insurance. An assessment in Ethiopia found that 49 per cent had never heard of insurance, 41 per cent did not know how it worked, and 25 per cent did not know where to find it (World Bank, 2018). More educated farmers and pastoralists portray higher demand and the less educated portray lower demand (Giné and Yang, 2009; Patt et al., 2009; Hill et al., 2013; Bogale, 2015; Okoffo et al., 2016; Takahashi et al., 2016; Abugri et al., 2017; Bishu et al., 2018; Fonta et al., 2018; Amare et al., 2019; Janzen and Carter, 2019; Vasilaky et al., 2019). Literacy is not only important in order to know about insurance but also to correctly understand insurance contracts. When farmers are not able to understand concepts like basis risk, demand remains low (Stoeffler and Opuz, 2020). Education and information tend to run concurrently. While insurance providers might not change the literacy skills of the farmers, they can provide more information. The evidence shows that where information has been provided, farmers and pastoralists increase their understanding of insurance as well as demand (Patt et al., 2009; Lybbert et al., 2010; McPeak et al., 2010; Takahashi et al., 2016; Belissa et al., 2019; Vasilaky et al., 2019; Ali et al., 2020a). Information might be provided through games (McPeak et al., 2010; Vasilaky et al., 2019), information brochures (Takahashi et al., 2016), or training sessions (Dercon et al., 2014). However, it is not merely information or literacy, but a better understanding 
of insurance concepts and underlying mechanisms that is is crucial. While farmers might know more about insurance, demand does not seem to improve with knowledge automatically (Takahashi et al., 2016). Exposure needs to be consistent to nudge demand. Previous experience also matters in that farmers who have previously insured are more informed and hence more likely to purchase insurance again (Karlan et al., 2014; Castellani and Viganò, 2017; Belissa et al., 2019). Insurance providers could therefore invest in increasing insurance awareness through more marketing campaigns and training.

\subsection{Behavioural and socio-cultural factors}

Farmers and pastoralists are also influenced by behavioural, social and cultural factors in their decisions to purchase insurance. These factors are portrayed through risk perceptions, trust and, in some communities, cultural and religious beliefs play a role. We elaborate on these below.

\subsubsection{Risk perceptions and attitudes}

Generally, risk perception can be in three dimensions. (1) Risk aversion - where individuals have a concave utility function in that as risk increases, they are more likely to adopt risk mitigation mechanisms. (2) Risk neutrality - where individuals are indifferent to risk. (3) Risk loving - where individuals portray a convex utility function such that they increase risky ventures even when the possibility of loss is high. Risk-averse farmers are more likely to demand insurance more than risk-loving and risk-neutral farmers. Risk aversion in agricultural insurance can be categorised in two aspects. The first is risk aversion towards the probability of a weather shock happening and the farmers having losses. For this kind of risk aversion, insurance is always attractive (Outreville, 1998). An increase in risk aversion is associated with more insurance take-up (Belissa et al., 2020; Haile et al., 2020 b). Risk aversion is further informed by how individuals assess the probability of a shock happening. Previous shocks provide reference points on which to assess possible losses or losses averted (gains) from a future shock and therefore influence risk aversion (Lybbert et al., 2010; Hill et al., 2013; Karlan et al., 2014; Bogale, 2015; Fonta et al., 2018; Janzen and Carter, 2019). For instance, previous shocks expressed in the units of tropical livestock units lost in the previous year was associated with an increase in demand for insurance (Janzen and Carter, 2019). Previous shocks can also alert individuals to undertake protective and precautionary actions including risk-averse behaviour and hence increase the likelihood of purchasing insurance (Clarke, 2016).

However, farmers might underestimate the probability of weather shocks and therefore demand less insurance (Abugri et al., 2017; Dougherty et al., 2019). When farmers underestimate the probability of several shocks and insurance failures such as basis risk, they develop compound risk aversion, which greatly affects demand as experimental evidence from Mali shows (Elabed et al., 2013; Elabed and Carter, 2015). Compound risk aversion is related to ambiguity aversion. Ambiguity aversion occurs when farmers are not able to correctly interpret the value of new technologies such as agricultural insurance (Bryan, 2019). Evaluating experiments in Kenya and Malawi, Bryan (2019) found that ambiguity averse farmers insured less. However, what seems to be important is not just risk aversion but how the insurance provider frames the narrative. While risk-averse farmers might demand less insurance, when the narrative is framed from a loss dimension, loss-averse farmers are more likely to purchase insurance (Visser et al., 2020) because they prefer the certainty of non-decreasing welfare with insurance (Serfilippi et al., 2020). In an experiment in Burkina Faso, Serfilippi et al. (2020) found 
that when farmers were offered a premium rebate contract, where they received the equivalent of their premiums in a bad year, they demanded higher insurance than when the contract did not specify a rebate but rather conventional coverage. An additional 41 per cent willingness to pay emanated simply from this framing as farmers' welfare would decrease less with premium rebate than with no rebates. An appropriate framing could overcome some component of risk aversion and attract demand.

\subsubsection{Low trust}

Distrust in insurance products and insurance providers reduces agricultural insurance demand among farmers and pastoralists pastoralists (Patt et al., 2009; Suarez and Linnerooth-Bayer, 2010; Karlan et al., 2014; Tadesse et al., 2017). Low trust is partly related to education and inadequate knowledge and information about formal insurance. Farmers are therefore not able to understand how new technologies such as insurance work (McPeak et al., 2010; Bryan, 2019). Farmers reveal distrust in: (1) the insurance product, (2) the insurance providers, (3) the technology on which insurance is based, and (4) interpersonal trust among individuals (Platteau et al., 2017). Lack of trust in the product can be improved if farmers receive better information about insurance (see section 4.4). Distrust in insurers might be related to three issues. First, insurers generally have a low presence in rural areas in SSA. Agricultural insurance is generally new and has not proliferated in rural areas. Rural farmers are less likely to trust institutions that they do not have a previous relationship with and do not know well. With this bottleneck, insurance providers could use channels of higher trust such as community-based groups. We expand on this issue in sub-section 4.5.5. Other channels might include well-known financial institutions, such as banks and microfinance organisations, and input retailers (World Bank, 2018) or farmer organisations (Patt et al., 2009). In some instances, farmers trust governments over commercial insurance companies (Tadesse et al., 2017). In general, it can be very useful to leverage existing trusted institutions rather than starting new operations. It might also be useful if prospective providers conduct sufficient market research before they launch operations. Strategies to reduce basis risk can increase trust in indices.

\subsubsection{Farmer participation}

To increase insurance acceptability, farmer-driven product design should be fostered and prioritised, especially at early design stages (Patt et al., 2009; Greatrex et al., 2015). Patt et al. (2009) provided two examples of participation that increased trust. In Ethiopia, farmers and experts worked together using local materials to assemble historical rainfall distribution data of the area. Farmer provided information was found to highly correlate with historical meteorological data, and insurance experts, therefore, used it to calculate the monthly weights for rainfall in these areas. The second example was in Malawi where through farmer workshops, farmers participated in calculating the payout levels under different rainfall regimes, increasing both their understanding and building trust in the products. Leblois et al. (2014b) gave another dimension of farmer participation. They compared an index constructed with a simulated cotton sowing date with that provided by the farmers, collected through a farmer association. They found that the index that used farmer-provided sowing date data was preferred and also reduced basis risk more than the simulation-based product. Indeed, in their example, it was easy to access this farmer provided data. However, it might be at a cost to insurance providers in the absence of such a farmer organisation that records this kind of data. The evolving picture-based insurance in Ethiopia (Porter et al., 2020) and Kenya (ACRE Africa, 
2020) improves farmer participation in monitoring and loss verification. It is, therefore, able to contribute to reducing basis risk as well as increasing farmer trust through their participation.

\subsubsection{Cultural perceptions}

We discuss culture in two dimensions: first, the general position of women in society and second, the influence of religion. While women comprise a very large demographic within farming households, their roles regarding decision making in agriculture investments are largely limited by restrictive cultural norms (Fisher and Carr, 2015; Perez et al., 2015). Such barriers also permeate insurance adoption (Delavallade et al., 2015; Abugri et al., 2017; Born et al., 2019) among others. Since women farmers are likely to be poorer than men farmers, their involvement in insurance is limited (Delavallade et al., 2015; Abugri et al., 2017; Fonta et al., 2018). Though in some cases there are no significant differences between women and men farmers regarding insurance adoption (Bageant and Barrett, 2017), gendered data on the adoption of insurance is not broadly available (Born et al., 2019), and this limits analysis of how women farmers are affected in agricultural insurance provision. Such data would be essential in tailoring insurance products to cater to any gender-disaggregated needs (Fletschner and Kenney, 2014; Born et al., 2019).

Regarding the influence of religion, individual beliefs might conflict with marketoriented technologies such as insurance. This issue has been observed in northern Kenya (Johnson et al., 2019) and Niger (Fava et al., 2018), both predominantly Muslim regions. In Kenya, Johnson et al. (2019) qualitatively detail the case of index-based livestock insurance in northern Kenya regarding expectations, aspirations and the challenges experienced. In their narrative, they show that some of the difficulties related to low sales emanated from the way predominantly Muslim communities viewed profit-making insurance products as not culturally and religiously permissible under the Sharia Law. To build more trust in insurance, a new provider that adhered to the cultural and religious preferences of the communities was introduced in the market (Banerjee et al., 2017; Johnson et al., 2019). The result was an increase in trust, retention of a higher number of local agents (Banerjee et al., 2017), expansion into other areas and insuring of greater numbers of livestock units (Johnson et al., 2019). Though the costs of operations remained high, and the model was costly (Banerjee et al., 2017), the positive effects on trust-building and expansion were clear. With this experience, the inception of index insurance in Niger was purposefully made sharia-compliant (Fava et al., 2018). This suggests that insurance providers can, after learning, leverage such normatively hidden preferences such as religion and make their products popular and attractive. Moreover, insurance, being a financial product, would need to heed different norms that govern financial products across different regions.

\subsubsection{Offering insurance to groups}

On a theoretical level, De Janvry et al. (2014) offered several reasons why insurance provided through groups should be considered more. First, community-based informal social support and risk management organisations are very important in building trust. Social support groups are formed for social support in all kinds of idiosyncratic shocks to households and have gained prominence mainly for easing targeting difficulties due to their near-universal coverage community (Bold and Dercon, 2014). They, therefore, act as effective points of information dissemination and reduce the costs of reaching clients (Bhattamishra and Barrett, 2010). 
Secondly, these institutions already have a good understanding of insurance since they already provide informal insurance under the basis of risk-sharing. Thirdly, the nature of their reciprocal relationships (Fafchamps, 2011) implies that trust levels in these organisations are generally high. Providers of agricultural insurance might find them appropriate platforms for introducing and distributing insurance (Trærup, 2012; Dercon et al., 2014; Belissa et al., 2019). Because individuals trust groups in which they already have informal membership, they prefer group-based contracts to individual contracts (Hill et al., 2013; Dercon et al., 2014; Sibiko et al., 2018; Belissa et al., 2019). Belissa et al. (2019) observed that in contrast to individual index insurance take-up of only 8 per cent, when farmers had the offer of insurance through their informal groups, takeup rates increased to 43 per cent. Some of the benefits of group-based insurance include cost-effectiveness in information transmission and the pre-existing experience of risksharing (Dercon et al., 2014). Finally, groups enhance community social capital that enables the flow of information. In Ghana, Karlan et al. (2014) found that farmers who knew a farmer who had been insured and received a payout were more likely to purchase insurance in forthcoming years. Therefore, farmers improve their trust in insurance by observing the experiences of other farmers in their networks.

Nonetheless, there are three important caveats to make in the encouragement of group-based contracts. The first is the complexity of making legally-binding agreements with informal groups. Informal groups do not have a legal framework in which they operate beyond the informal trust and norms of group members. In such cases, even when contracts with informal groups are preferred, providers cannot enter into contracts with them (Dercon et al., 2014). Providers offering group contracts would, therefore, have to make prudent decisions, including investing in contract monitoring at the individual level for each individual in a group.

Secondly, there might be fears that group contracts might promote moral hazard if farmers change their behaviour on issues such as farm investment. There is a need for more research to test these fears. One such research study is Bulte et al. (2019) who tested whether taking insurance made farmers invest less in their farms in Kenya. They did not find supporting evidence; instead they found that insured farmers invested more in their farms. Stoeffler et al. (2020) arrived at a similar result in Burkina Faso, where they observed that enrolment in insurance encouraged intensive farm investments.

The third caveat, related to moral hazard, is the concerns of free riding and crowding out informal social insurance systems. The argument is that formal insurance, promoted and provided through informal groups, weakens informal mechanisms and hence crowds out existing informal social protection mechanisms. Though the evidence is mixed, free riding might not be ruled out (De Janvry et al., 2014), and it has been observed in other insurance types (such as health insurance). Two recent studies both assessing crowding out due to index-based insurance in Ethiopia do not find confirmatory evidence (Matsuda et al., 2019; Takahashi et al., 2019). While evidence of crowding out is still scarce, suppliers would need to closely monitor the behaviour of the insured and check that such innovations do not disrupt existing systems.

\subsection{The role of governments}

So far, this review has explored demand from farmers and supply from insurance providers. A key connection to complete the circle is the role of governments in both demand and supply dimensions. Meso- to macro-level factors might pose a challenge 
for a single insurance provider. Many providers require market regulation and policy oversight and governments can induce demand through various support strategies to farmers. In this section, we consider the role of governments in: (1) reducing the costs of delivering insurance through better market coordination, (2) providing both consumer and provider subsidies, and (3) developing and updating policies to suit an increasingly dynamic market.

\subsubsection{Reducing the costs of delivering insurance}

Whereas other kinds of insurance (such as health or motor insurance) have a concept of self-protection such as better use of preventive health services or more disciplined driving (which in turn might lower premiums), farmers do not have much leverage over the weather. Moreover, climate change increases the frequency and intensity of weatherrelated risks, and most shocks are covariate in nature. Agricultural insurance, therefore, becomes a high-frequency, high loss insurance type making it more complicated than other kinds of insurance.

The cost of commercially viable agricultural insurance is therefore high and prohibitive to both the provider and farmers. The costs of providing agricultural insurance can be subdivided into start-up costs, operational costs and transaction costs. Insurance companies are required to have sufficient reserve capital to ascertain meeting insurees' claims when they arise. Providers also have to pay reinsurance costs to insure their losses too. For high loss events such as weather shocks, thresholds for reserve capital are high. The predictable losses increase the cost of reinsurance which is in turn transmitted to the consumers through increased premiums (Miranda and Mulangu, 2016). The second type of costs is related to operational costs associated with development, maintenance and monitoring of indices and insurance payoff thresholds. The infrastructure to acquire and process data needed for the indices can be expensive for single and small providers. For more precise insurance products, providers require more information, even up to plot-level data. The third dimension of costs is transaction costs. These include administrative costs incurred to reach the farmers and pastoralists, especially in remote areas. Where there is low demand, the costs of maintaining insurance company staff in remote areas are high (Johnson et al., 2019). A combination of all these costs puts insurance providers at risk (Meze-Hausken et al., 2009). Insurance providers can ease some of the costs through better coordination mechanisms. For instance, many smaller micro-insurance providers can work in association and thus pool both human and capital resources together to afford some of the costs of market entry (Meze-Hausken et al., 2009).

Governments can reduce costs through the provision of infrastructure. Infrastructure such as weather stations and their maintenance can be provided as public services. While these exist in many countries, their sparse distribution (Webster, 2013; Parker, 2015) suggests that governments need to invest more in this infrastructure to make weather services more affordable and available even for commercial use (Georgeson et al., 2017). Governments can also provide risk layering and aggregation which is a process in which overall risk is classified across levels of severity to provide insurance and reinsurance services. Governments can then provide insurance and reinsurance services to providers involved in highest risk and high severity events across geographical spaces. There is no published example of these services in Africa to include in this review, however, the Mongolian Index-Based Livestock Insurance Programme (Rao et al., 2015) and the crop insurance programme in Tajikistan (Weber et al., 2015) might provide some insights 
for Africa. ${ }^{2}$ In Tajikistan, Weber et al. (2015) discuss insurance products designed with inter-regional and intra-regional risk aggregation and risk coverage scenarios to achieve risk reduction. In Mongolia, livestock losses are insured at three levels (Rao et al., 2015; Hohl, 2019: 299). At 6 per cent mortality, pastoralists are required to self-insure for this low risk. Between 6 and 30 per cent of mortality, insurance providers cover losses. At mortalities of more than 30 per cent, insurance providers are also adversely affected and unable to provide effective coverage. In turn, the Agricultural Reinsurance Company covers the losses of both the insurance provider and the pastoralists. In both cases, the government had a dominant role in providing meso-level insurance thus enabling insurance providers to function effectively. A comparable example from Africa is the ARC that provides drought risk pooling reinsurance to countries through its annual risk pools (Awondo, 2019). Similar to sub-regions in Tajikistan, Awondo (2019) found that as more member countries join the ARC risk pool, the risk was better covered. Moreover, the buffer fund per country, required to cover extreme drought events, decreases as more countries participate, indicating strong benefits for risk pooling.

\subsubsection{Subsidies and other public goods}

Governments can also provide subsidies to make insurance affordable. Almost all agricultural insurance programmes in both high and low-income countries already have some form of subsidisation. The level of subsidies determines how much insurance is made affordable. Moreover, providing demand (premium) subsidies increases takeup rates and take-up does not decrease when subsidies end (see section 4.3.1). Mahul and Stutley (2010) suggested eight reasons why governments should support agricultural insurance programmes. These included systemic risk associated with agriculture risks; information asymmetries between providers and insurance seekers; weaknesses and insufficiency of post disasters programmes (especially with building sustainable resilience); limited international reinsurance markets; limited and expensive agriculture risk market infrastructure (such as weather stations); low-risk awareness, lack of (formal) insurance culture; and finally, regulatory impediments.

Furthermore, governments can support providers through provider subsidies (Mahul and Stutley, 2010; Hazell et al., 2017). Provider market enhancing subsidies aim at developing strong risk market infrastructure and might include subsidies for infrastructure improvements, provider start-up costs, market stabilisation subsidies and reinsurance subsidies (Miranda and Farrin, 2012). One example of such subsidies is the joint World Bank - Government of Kenya initiative that supports public-private partnerships to provide premium subsidies ranging from 50 to 100 per cent of premiums for the most vulnerable pastoralists (Hazell et al., 2017). Moreover, with more purpose and coordination, these subsidies can be provided at cross-country and regional levels. For instance, countries joining the Africa Disaster Risk Financing Facility receive a 50 per cent subsidy upon entry (ARC, 2018). The success of broad subsidy programmes needs both fiscal discipline and a view beyond political motivations. Political electoral motivations led to the withdrawal of Kenya and Malawi from the 2016/17 ARC risk pool (Hohl, 2019: 288) and such happenings could jeopardise the success of the industry.

\footnotetext{
${ }^{2}$ These two papers were not part of the literature search process and have been referenced only to expound on the understanding of meso and macro insurance risk layering and reinsurance.
} 


\subsubsection{Policy, regulation and legal environment}

Finally, the key role of government support in developing policies, regulating the markets and creating an enabling environment for insurance providers, cannot be overstated. There are two dimensions of how governments might act. First, governments as the main market player through the provision of other agricultural services such as extension and farm inputs can include agricultural insurance in its core services provided such as in Zambia (World Bank, 2019). Other relatively larger programmes such as ACRE Africa in East Africa also provide insurance alongside farm inputs. This combination of services with inputs is often referred to as bundling. Although evidence on bundling insurance with other services is clear (see section 4.2.4) we do not have strong views regarding making programmes compulsory as is the case in Zambia. However, national governments can take decisive and cost-effective actions especially by leveraging an already existing infrastructure of delivering other services, and mandatory insurance might be one of the options.

Governments can also provide regulation and market coordination functions. The principal role of the government should be to address market and regulatory imperfections so that private insurance and reinsurance providers can participate (Mahul and Stutley, 2010). Market regulation is therefore necessary to both farmers and pastoralists on the one hand and insurance providers on the other. It protects farmers from underhanded and predatory behaviour from providers and creates a competitive environment for providers. From a demand perspective, without government regulation, there is a high likelihood of a low product quality equilibrium (Clarke and Wren-Lewis, 2013; Carter and Chiu, 2018), which in turn hurts farmers through poor, unhelpful products. From a supply-side perspective, regulation keeps prices in check to avoid high premiums and low demand and finally exiting by providers due to poor markets.

Effective regulation ought to be embedded in the law and regulatory organisations have to be legally empowered to act to balance markets. One major challenge is that agricultural insurance is relatively new in many SSA countries and laws and regulations on it are nonexistent or still in the early stages of development (Jegede et al., 2020; Onyiriuba et al., 2020). Countries, therefore, need to re-evaluate their policies and laws, given recent innovations. There is some progress but it could be made faster with better in-country and across countries' coordination. Two examples of progress on this front are the West African Inter-African Conference of the Insurance Markets (CIMA) countries and in Kenya. Pre-2012, the CIMA countries operating a regional regulatory body on insurance and reinsurance had only one article regarding agricultural insurance (Mahul and Stutley, 2010). In 2012, 14 CIMA countries adopted a new law that allowed regulation and oversight of agricultural insurance (World Bank, 2015a). In Kenya, the government has updated the Insurance Bill and expanded the jurisdiction of the Insurance Regulatory Authority to agricultural insurance (World Bank, 2015b). These two examples provide opportunities on how countries and inter-country bodies can update their laws, regulations and policies to provide more space for insurance providers while setting standards with emerging technologies.

\section{Conclusion}

In this comprehensive review, we assessed a wide range of qualitative and quantitative peer-reviewed and grey literature to build on existing knowledge on the factors that influence the take-up of agricultural insurance and how take-up might be encouraged. The review sheds light on six main themes. These include: (1) product quality; (2) product 
design; (3) household incomes and investments under limited budgets; (4) education, information and knowledge of insurance; (5) behavioural preferences and cultural barriers; and (6) the role of governments in providing an enabling, stable and efficient market.

It is worth noting that agricultural insurance is not and should not be viewed as a singular magic answer to all weather-related problems that farmers face. It is rather part of a range of risk management options, alongside other instruments such as cash transfers and informal risk-sharing and risk management strategies. Comparing it with cash transfers, the review invites policymakers to consider the costs and opportunities between what Janzen et al. (2020) refer to as 'reactive' social protection versus 'proactive' social protection with a long term view. Moreover, the trend of adoption of cash transfers might also provide a policy-learning path for agricultural insurance. Based on the Zambian example, governments might have to integrate insurance into existing extension and farm input programmes as evidence shows that combining these can provide larger coverage at lower costs. In regions where insurance is relatively new, providers might need to invest in information services, promoting awareness and building trust. Participation is crucial as farmers are not only consumers but also hold important information that might make insurance provision more efficient. Finally, the role of governments cannot be overstated. Governments can respond not only through the provision of demand and supply subsidies but also by designing policies and laws that enable the growth of agricultural insurance markets. Strategically, governments can join regional risk pools, which further attracts private providers and strengthens reinsurance services. Ultimately, SSA will benefit from increased adoption of well-designed insurance products and services that take into consideration the local context for all players in the agricultural insurance markets, with the support of local and regional governments - particularly in the face of climate change, and its current and projected adverse effects in the region.

Supplementary material. The supplementary material for this article can be found at https://doi.org/10. 1017/S1355770X21000085

\section{References}

Abugri SA, Amikuzuno J and Daadi EB (2017) Looking out for a better mitigation strategy: smallholder farmers' willingness to pay for drought-index crop insurance premium in the Northern Region of Ghana. Agriculture and Food Security 6, 1-9.

ACRE Africa (2020) Our products: Picture based insurance (PBI). Available at https://acreafrica.com/ our-products-picture-based-insurance-pbi/.

Adesimi AA and Alli KM (1980) Crop yield insurance programme: a suggested policy approach to stabilise farm income in the old western state of Nigeria. Agricultural Administration 7, 97-106.

Ahmed S, McIntosh C and Sarris A (2020) The impact of commercial rainfall index insurance: experimental evidence from Ethiopia. American Journal of Agricultural Economics 102, 1154-1176.

Ali E, Egbendewe AYG, Abdoulaye T and Sarpong DB (2020a) Willingness to pay for weather index-based insurance in semi-subsistence agriculture: evidence from northern Togo agriculture. Climate Policy 20, 534-547.

Ali W, Abdulai A and Mishra AK (2020b) Recent advances in the analyses of demand for agricultural insurance in developing and emerging countries. Annual Review of Resource Economics 12, 411-430.

Allen IV JE (2018) Are agricultural markets more developed around cities? Testing for urban heterogeneity in separability in Tanzania. Food Policy 78, 199-212.

Alli KM (1980) Analysis of the prospects and problems of agricultural insurance in a developing country: the case of Nigeria. Agricultural Administration 7, 25-33. 
Amare A, Simane B, Nyangaga J, De A, Hamza D and Gurmessa B (2019) Index-based livestock insurance to manage climate risks in Borena zone of southern Oromia, Ethiopia. Climate Risk Management 25, 100191.

ARC (2018) Press Release: African Risk Capacity lauds the approval of the Africa Disaster Risks Financing Facility. Available at https://www.africanriskcapacity.org/2018/11/05/press-release-african-riskcapacity-la-risk-capacity-lauds-the-approval-of-the-africa-disaster-risks-financing-facility-by/.

Atlas Magazine (2017) Agricultural insurance in Africa and Middle East. Atlas Magazine No. 143. Available at https://www.atlas-mag.net/sites/default/files/AtlasMagazine_2017-07_en.pdf.

Awondo SN (2019) Efficiency of region-wide catastrophic weather risk pools: implications for African Risk Capacity insurance program. Journal of Development Economics 136, 111-118.

Awondo SN, Kostandini G and Erenstein O (2020) Multi-site bundling of drought tolerant maize varieties and index insurance. Journal of Agricultural Economics 71, 239-259.

Bageant ER and Barrett CB (2017) Are there gender differences in demand for index-based livestock insurance? Journal of Development Studies 53, 932-952.

Banerjee R, Khalai DC, Galgallo D and Mude A (2017) Improving the Agency Model in Distribution of Index Based Livestock Insurance (IBLI) - A Study of Takaful Insurance of Africa (ILRI Research Report 45). Nairobi, Kenya.

Barré T, Stoeffler Q and Carter M (2016) Assessing index insurance: conceptual approach and empirical illustration from Burkina Faso. Unpublished. Available at http://quentinstoeffler.weebly.com/uploads/4/ 0/2/6/40265181/assessing_index_insurance_csae2016-908.pdf.

Belissa T, Bulte E, Cecchi F, Gangopadhyay S and Lensink R (2019) Liquidity constraints, informal institutions, and the adoption of weather insurance: a randomized controlled trial in Ethiopia. Journal of Development Economics 140, 269-278.

Belissa T, Lensink R and van Asseldonk M (2020) Risk and ambiguity aversion behavior in index-based insurance uptake decisions: experimental evidence from Ethiopia. Journal of Economic Behavior \& Organization 180, 718-730.

Berg A, Quirion P and Sultan B (2009) Weather-index drought insurance in Burkina-Faso: assessment of its potential interest to farmers. Weather, Climate, and Society 1, 71-84.

Bhattamishra R and Barrett CB (2010) Community-based risk management arrangements: a review. World Development 38, 923-932.

Binswanger-Mkhize HP (2012) Is there too much hype about index-based agricultural insurance? Journal of Development Studies 48, 187-200.

Bishu KG, Lahiff E, O'Reilly S and Gebregziabher M (2018) Drivers of farmers' cattle insurance decisions: evidence from smallholders in northern Ethiopia. Agrekon 57, 40-48.

Bogale A (2015) Weather-indexed insurance: an elusive or achievable adaptation strategy to climate variability and change for smallholder farmers in Ethiopia. Climate and Development 7, 246-256.

Bold T and Dercon S (2014) Insurance Companies of the Poor. CEPR Discussion Paper No. 10278. London: Centre for Economic Policy Research.

Born L, Spillane C and Murray U (2019) Integrating gender into index-based agricultural insurance: a focus on South Africa. Development in Practice 29, 409-423.

Börner J, Shively G, Wunder S and Wyman M (2015) How do rural households cope with economic shocks? Insights from global data using hierarchical analysis. Journal of Agricultural Economics 66, 392-414.

Bryan G (2019) Ambiguity aversion decreases the impact of partial insurance: evidence from African farmers. Journal of European Economic Association 17, 1428-1469.

Bulte E, Cecchi F, Lensink R, Marr A and van Asseldonk M (2019) Does bundling crop insurance with certified seeds crowd-in investments? Experimental evidence from Kenya. Journal of Economic Behavior \& Organization 180, 744-757.

Burger OE (1939) Agricultural insurance in South Africa. South African Journal of Economics 7, 410-425.

Carter M and Chiu T (2018) A minimum quality standard to ensure index insurance contracts do no harm. Available at https://www.agrilinks.org/sites/default/files/ama_brief_2018-04_-_carter_mqs_ index_insurance-web.pdf.

Carter MR and Janzen SA (2018) Social protection in the face of climate change: targeting principles and financing mechanisms. Environment and Development Economics 23, 369-389. 
Carter MR, Cheng L and Sarris A (2016) Where and how index insurance can boost the adoption of improved agricultural technologies. Journal of Development Economics 118, 59-71.

Carter M, de Janvry A, Sadoulet E and Sarris A (2017) Index insurance for developing country agriculture: a reassessment. Annual Review of Resource Economics 9, 421-438.

Casaburi L and Willis J (2018) Time vs. state in insurance: experimental evidence from contract farming in Kenya. American Economic Review 108, 3778-3813.

Castellani D (2015) Perceived basis risk and the heterogeneous demand for weather derivatives in southern Ethiopia. Savings and Development 39, 1-36.

Castellani D and Viganò L (2017) Does willingness-to-pay for weather index-based insurance follow covariant shocks? International Journal of Bank Marketing 35, 516-539.

Ceballos F, Kramer B and Robles M (2019) The feasibility of picture-based insurance (PBI): smartphone pictures for affordable crop insurance. Development Engineering 4, 100042.

Chantarat S, Mude AG, Barrett CB and Turvey CG (2017) Welfare impacts of index insurance in the presence of a poverty trap. World Development 94, 119-138.

Clarke DJ (2016) A theory of rational demand for index insurance. American Economic Journal: Microeconomics 8, 283-306.

Clarke D and Wren-Lewis L (2013) Learning from lemons: the role of government in index insurance for individuals. FERDI Policy Brief B70, 1-7.

Coe R and Stern RD (2011) Assessing and addressing climate-induced risk in sub-Saharan rainfed agriculture: lessons learned. Experimental Agriculture 47, 395-410.

Coleman E, Dick W, Gilliams S, Piccard I, Rispoli F and Stoppa A (2017) Remote Sensing for Index Insurance: An Overview of Findings and Lessons Learned for Smallholder Agriculture. Rome: International Fund of Agricultural Development (IFAD).

De Janvry A, Dequiedt V and Sadoulet E (2014) The demand for insurance against common shocks. Journal of Development Economics 106, 227-238.

Delavallade C, Dizon F, Hill RV and Petraud JP (2015) Managing Risk with Insurance and Savings: Experimental Evidence for Male and Female Farm Managers in West Africa. Washington D.C.: International Food Policy Research Institute (IFPRI).

De Oto L, Vrieling A, Fava F and De Bie KCAJM (2019) Exploring improvements to the design of an operational seasonal forage scarcity index from NDVI time series for livestock insurance in East Africa. International Journal of Applied Earth Observation and Geoinformation 82, 101885.

Dercon S, Hill RV, Clarke D, Outes-Leon I and Seyoum Taffesse A (2014) Offering rainfall insurance to informal insurance groups: evidence from a field experiment in Ethiopia. Journal of Development Economics 106, 132-143.

Díaz Nieto J, Cook SE, Läderach P, Myles J and Jones PG (2010) Rainfall index insurance to help smallholder farmers manage drought risk. Climate and Development 2, 233-247.

Dillon B and Barrett CB (2017) Agricultural factor markets in Sub-Saharan Africa: an updated view with formal tests for market failure. Food Policy 67, 64-77.

Di Marcantonio F and Kayitakire F (2017) Review of pilot projects on index-based insurance in Africa: insights and lessons learned. In Tiepolo M, Pezzoli A and Tarchiani V (eds), Renewing Local Planning to Face Climate Change in the Tropics. Rome: Springer, pp. 323-341.

Dougherty JP, Flatnes JE, Gallenstein RA, Miranda MJ and Sam AG (2019) Climate change and index insurance demand: evidence from a framed field experiment in Tanzania. Journal of Economic Behavior \& Organization 175, 155-184.

Duru MJ (2016) Too certain to invest ? Public safety nets and insurance markets in Ethiopia. World Development 78, 37-51.

Elabed G and Carter MR (2015) Compound-risk aversion, ambiguity and the willingness to pay for microinsurance. Journal of Economic Behavior \& Organization 118, 150-166.

Elabed G, Bellemare MF, Carter MR and Guirkinger C (2013) Managing basis risk with multiscale index insurance. Agricultural Economics 44, 419-431.

Enenkel M, Osgood D and Powell B (2017) The added value of satellite soil moisture for agricultural index insurance. In Petropoulos GP and Islam T (eds), Remote Sensing of Hydrometeorological Hazards. Boca Raton, Florida: CRC Press, pp. 69-84. 
Enenkel M, Osgood D, Anderson M, Powell B, McCarty J, Neigh C, Carroll M, Wooten M, Husak G, Hain C, Brown M et al. (2019) Exploiting the convergence of evidence in satellite data for advanced weather index insurance design. Weather, Climate, and Society 11, 65-93.

Fafchamps M (2011) Risk sharing between households. In Benhabib J, Bisin A and Jackson MO (eds), Handbook of Social Economics, vol. 1. Amsterdam: Elsevier B.V., pp. 1255-1279.

FAO (2015) The Impact of Disasters on Agriculture and Food Security. Rome: Food and Agriculture Organization.

Fava F, Upton J, Banerjee R, Taye M and Mude A (2018) Pre-Feasibility Study for Index-Based Livestock Insurance in Niger (ILRI Research Report 51). Nairobi, Kenya: International Livestock Research Institute.

Fisher M and Carr ER (2015) The influence of gendered roles and responsibilities on the adoption of technologies that mitigate drought risk: the case of drought-tolerant maize seed in eastern Uganda. Global Environmental Change 35, 82-92.

Fisher E, Hellin J, Greatrex H and Jensen N (2019) Index insurance and climate risk management: addressing social equity. Development Policy Review 37, 581-602.

Flatnes JE, Carter MR and Mercovich R (2018) Improving the quality of index insurance with a satellitebased conditional audit contract. Unpublished Working Paper. Available at https://basis.ucdavis.edu/ sites/g/files/dgvnsk466/files/2018-11/FlatnesCarterconditionalauditTanzania.pdf.

Fletschner D and Kenney L (2014) Rural women's access to financial services: credit, savings, and insurance. In Quisumbing AR, Meinzen-Dick R, Raney TL, Croppenstedt A, Behrman JA and Peterman A (eds), Agriculture: Closing the Knowledge Gap. Netherlands: Springer, pp. 187-208.

Fonta WM, Sanfo S, Kedir AM and Thiam DR (2018) Estimating farmers' willingness to pay for weather index-based crop insurance uptake in West Africa: insight from a pilot initiative in Southwestern Burkina Faso. Agricultural and Food Economics 6, 11.

Gallenstein RA, Mishra K, Sam AG and Miranda MJ (2019) Willingness to pay for insured loans in Northern Ghana. Journal of Agricultural Economics 70, 640-662.

Gebrekidan T, Guo Y, Bi S, Wang J, Zhang C, Wang J and Lyu K (2019) Effect of index-based livestock insurance on herd offtake: evidence from the Borena zone of southern Ethiopia. Climate Risk Management 23, 67-77.

Georgeson L, Maslin M and Poessinouw M (2017) Global disparity in the supply of commercial weather and climate information services. Science Advances 3, 1-10.

Giné X and Yang D (2009) Insurance, credit, and technology adoption: field experimental evidence from Malawi. Journal of Development Economics 89, 1-11.

Giné X, Karlan D and Ngatia M (2014) Social networks, financial literacy, and index insurance: evidence from a randomized experiment in Kenya. In Lundberg M and Mulaj F (eds), Enhancing Financial Capability and Behavior in Low and Middle-Income Countries. Washington, DC: The World Bank, pp. 195-208.

Greatrex H, Hansen J, Garvin S, Diro R, Blakeley S, Le Guen M et al. (2015) Scaling Up Index Insurance for Smallholder Farmers: Recent Evidence and Insights (CCAFS Report No 14). Copenhagen, Denmark: CGIAR Research Program on Climate Change, Agriculture and Food Security.

GSMA (2015) Mobile Insurance, Savings and Credit Report. London: GSMA.

Haile KK, Nillesen E and Tirivayi N (2020b) Impact of formal climate risk transfer mechanisms on riskaversion: empirical evidence from rural Ethiopia. World Development 130, 104930.

Haile GG, Tang Q, Hosseini-Moghari S-M, Liu X, Gebremicael TG, Leng G et al. (2020a) Projected impacts of climate change on drought patterns over East Africa. Earth's Future 8, e2020EF001502.

Hazell P, Sberro-Kessler R and Varangis P (2017) When and how Should Agricultural Insurance be Subsidized? Issues and Good Practices. Washington D.C.: International Labour Organization (ILO) and International Finance Corporation (IFC).

Hellmuth ME, Osgood DE, Hess U, Moorhead A and Bhojwani H (eds) (2009) Index Insurance and Climate Risk: Prospects for Development and Disaster Management. Climate and Society No. 2. New York: International Research Institute for Climate and Society (IRI), Columbia University.

Hess U and Hazell P (2016) Innovations and Emerging Trends in Agricultural Insurance: How Can We Transfer Natural Risks out of Rural Livelihooods To Empower and Protect People? Bonn and Escborn, Germany: Deutsche Gesellschaft für Internationale Zusammenarbeit (GIZ).

Hill RV, Hoddinott J and Kumar N (2013) Adoption of weather-index insurance: learning from willingness to pay among a panel of households in rural Ethiopia. Agricultural Economics 44, 385-398. 
Hochrainer-Stigler S, Van Der Velde M, Fritz S and Pflug G (2014) Remote sensing data for managing climate risks: index-based insurance and growth related applications for smallhold-farmers in Ethiopia. Climate Risk Management 6, 27-38.

Hohl RM (2019) Agricultural Risk Transfer. Chichester, West Sussex: John Wiley \& Sons.

Hufkens K, Melaas EK, Mann ML, Foster T, Ceballos F, Robles M and Kramer B (2019) Monitoring crop phenology using a smartphone based near-surface remote sensing approach. Agricultural and Forest Meteorology 265, 327-337.

Iturrioz R (2009) Agricultural Insurance. Primer series on insurance, issue 12. Washington, DC: The International Bank for Reconstruction and Development/The World Bank.

Janzen SA and Carter MR (2019) After the drought: the impact of microinsurance on consumption smoothing and asset protection. American Journal of Agricultural Economics 101, 651-671.

Janzen SA, Jensen ND and Mude AG (2016) Targeted social protection in a pastoralist economy: case study from Kenya. Revue Scientifique et Technique de l'OIE 35, 587-596.

Janzen SA, Carter MR and Ikegami M (2020) Can insurance alter poverty dynamics and reduce the cost of social protection in developing countries? Journal of Risk and Insurance, 1-32. doi:10.1111/jori.12322.

Jegede AO, Addaney M and Mokoena UC (2020) Climate change risk and insurance as an adaptation strategy: an enquiry into the regulatory framework of South Africa and Ghana. In Filho WH and Jacob D (eds), Handbook of Climate Services. Cham, Switzerland: Springer Nature, pp. 279-294.

Jensen ND and Barrett C (2017) Agricultural index insurance for development. Applied Economic Perspectives and Policy 39, 199-219.

Jensen ND, Barrett CB and Mude AG (2016) Index insurance quality and basis risk: evidence from Northern Kenya. American Journal of Agricultural Economics 98, 1450-1469.

Jensen ND, Barrett CB and Mude AG (2017a) Cash transfers and index insurance: a comparative impact analysis from northern Kenya. Journal of Development Economics 129, 14-28.

Jensen ND, Ikegami M and Mude A (2017b) Integrating social protection strategies for improved impact: a comparative evaluation of cash transfers and index insurance in Kenya. Geneva Papers on Risk and Insurance - Issues and Practice 42, 675-707.

Jensen ND, Mude AG and Barrett CB (2018) How basis risk and spatiotemporal adverse selection influence demand for index insurance: evidence from northern Kenya. Food Policy 74, 172-198.

Jensen, ND, Stoeffler Q, Fava F, Vrieling A, Atzberger C, Meroni M et al. (2019) Does the design matter? Comparing satellite-based indices for insuring pastoralists against drought. Ecological Economics 162, 59-73.

Johnson L, Wandera B, Jensen N and Banerjee R (2019) Competing expectations in an Index-Based Livestock Insurance Project. Journal of Development Studies 55, 1221-1239.

Karlan D, Osei R, Osei-Akoto I and Udry C (2014) Agricultural decisions after relaxing credit and risk constraints. Quarterly Journal of Economics 129, 597-652.

Leblois A, Quirion P, Alhassane A and Traoré S (2014a) Weather index drought insurance: an ex ante evaluation for millet growers in Niger. Environmental and Resource Economics 57, 527-551.

Leblois A, Quirion P and Sultan B (2014b) Price vs. weather shock hedging for cash crops: ex ante evaluation for cotton producers in Cameroon. Ecological Economics 101, 67-80.

Lowder SK, Skoet J and Raney T (2016) The number, size, and distribution of farms, smallholder farms, and family farms worldwide. World Development 87, 16-29.

Lybbert TJ and Carter MR (2015) Bundling drought tolerance and index insurance to reduce rural household vulnerability to drought. In Balisacan A, Chakravorty U and Ravago M-L (eds), Sustainable Economic Development: Resources, Environment, and Institutions. Kidlington, Oxford: Academic Press, pp. 401-414.

Lybbert TJ, Galarza FB, McPeak J, Barrett CB, Boucher SR, Carter MR et al. (2010) Dynamic field experiments in development economics. Agricultural and Resource Economics Review 39, 176-192.

Mahul O and Stutley CJ (2010) Government Support to Agricultural Insurance: Challenges and Options for Developing Countries. Washington, DC: The World Bank.

Marenya P, Smith VH and Nkonya E (2014) Relative preferences for soil conservation among smallholder farmers: evidence from Malawi. American Journal of Agricultural Economics 96, 690-710.

Marr A, Winkel A, van Asseldonk M, Lensink R and Bulte E (2016) Adoption and impact of indexinsurance and credit for smallholder farmers in developing countries: a systematic review. Agricultural Finance Review 76, 94-118. 
Matsuda A, Takahashi K and Ikegami M (2019) Direct and indirect impact of index-based livestock insurance in Southern Ethiopia. The Geneva Papers on Risk and Insurance - Issues and Practice 44, 481-502.

McIntosh C, Sarris A and Papadopoulos F (2013) Productivity, credit, risk, and the demand for weather index insurance in smallholder agriculture in Ethiopia. Agricultural Economics 44, 399-417.

McPeak J and Doss CR (2006) Are household production decisions cooperative? Evidence from pastoral migration and milk sales from northern Kenya. American Journal of Agricultural Economics 88, 525-541.

McPeak J, Chantarat S and Mude A (2010) Explaining index-based livestock insurance to pastoralists. Agricultural Finance Review 70, 333-352.

Meyer RL, Hazell PB and Varangis P (2018) Unlocking Smallholder Credit: Does Credit-Linked Agricultural Insurance Work? Washington, D.C.: International Labour Organization (ILO) and International Finance Corporation (IFC).

Meze-Hausken E, Patt A and Fritz S (2009) Reducing climate risk for micro-insurance providers in Africa: a case study of Ethiopia. Global Environmental Change 19, 66-73.

Miranda MJ and Farrin K (2012) Index insurance for developing countries. Applied Economic Perspectives and Policy 34, 391-427.

Miranda MJ and Mulangu FM (2016) Index Insurance for Agricultural Transformation in Africa. Accra, Ghana: Joint research between African Center for Economic Transformation (ACET) and Japan International Cooperation Agency Research institute (JICA-RI).

Morsink K, Clarke DJ and Mapfumo S (2016) How to Measure Whether Index Insurance Provides Reliable Protection. Policy Research Working Paper No. 7744. Washington, DC: World Bank.

Ng'ang'a SK, Bulte EH, Giller KE, Ndiwa NN, Kifugo SC, McIntire JM et al. (2016) Livestock wealth and social capital as insurance against climate risk: a case study of Samburu County in Kenya. Agricultural Systems 146, 44-54.

Norton M, Osgood D, Madajewicz M, Holthaus E, Peterson N, Diro R et al. (2014) Evidence of demand for index insurance: experimental games and commercial transactions in Ethiopia. Journal of Development Studies 50, 630-648.

Okoffo ED, Denkyirah EK, Adu DT and Fosu-Mensah BY (2016) A double-hurdle model estimation of cocoa farmers' willingness to pay for crop insurance in Ghana. SpringerPlus 5, 873.

Onyiriuba L, Okoro EUO and Ibe GI (2020) Strategic government policies on agricultural financing in African emerging markets. Agricultural Finance Review 80, 563-588.

Outreville JF (1998) Theory and Practice of Insurance. USA: Springer Science \& Business Media.

Parker HR (2015) Climate services in developing countries. Weather 70, 268-273.

Patt A, Peterson N, Carter M, Velez M, Hess U and Suarez P (2009) Making index insurance attractive to farmers. Mitigation and Adaptation Strategies for Global Change 14, 737-753.

Pautasso M (2013) Ten simple rules for writing a literature review. PLOS Computational Biology 9, e1003149.

Perez C, Jones EM, Kristjanson P, Cramer L, Thornton PK, Förch W and Barahona C (2015) How resilient are farming households and communities to a changing climate in Africa? A gender-based perspective. Global Environmental Change 34, 95-107.

Platteau JP, De Bock O and Gelade W (2017) The demand for microinsurance: a literature review. World Development 94, 139-156.

Porter M, Kramer B, Assefa K and Abzhamilova D (2020) Building trust in index insurance with picturebased crop audits in Ethiopia. Feed the Future Innovation Lab for Markets, Risk \& Resilience, University of California at Davis. Available at https://basis.ucdavis.edu/sites/g/files/dgvnsk466/files/2020-04/ MRRprojectin-brief-PorterEthiopia-FINAL.pdf.

Rao MP, Davi NK, D'Arrigo RD, Skees J, Nachin B, Leland C et al. (2015) Dzuds, droughts, and livestock mortality in Mongolia. Environmental Research Letters 10, 074012.

Reeves J (2017) The Wrong Model for Resilience: How G7-Backed Drought Insurance Failed Malawi, and What we Must Learn from it. Johannesburg, South Arica: Action Aid.

Ricome A, Affholder F, Gérard F, Muller B, Poeydebat C, Quirion P and Sall M (2017) Are subsidies to weather-index insurance the best use of public funds? A bio-economic farm model applied to the Senegalese groundnut basin. Agricultural Systems 156, 149-176.

Sandmark T, Debar J-C and Tatin-Jaleran C (2013) The Emergence and Development of Agriculture Microinsurance. Discussion Paper. Bonn/Eschbonn: Microinsurance Network, BMZ/GIZ. 
Serfilippi E, Carter M and Guirkinger C (2020) Insurance contracts when individuals "greatly value" certainty: results from a field experiment in Burkina Faso. Journal of Economic Behavior \& Organization 180, 731-743.

Sibiko KW, Veettil PC and Qaim M (2018) Small farmers' preferences for weather index insurance: insights from Kenya. Agriculture and Food Security 7, 1-14.

Siebert A (2016) Analysis of index insurance potential for adaptation to hydroclimatic risks in the West African Sahel. Weather, Climate, and Society 8, 265-283.

Smith VH (2016) Producer insurance and risk management options for smallholder farmers. World Bank Research Observer 31, 271-289.

Spinoni J, Barbosa P, Bucchignani E, Cassano J, Cavazos T, Christensen JH et al. (2020) Future global meteorological drought hot spots: a study based on CORDEX data. Journal of Climate 33, 3635-3661.

Stoeffler Q and Opuz G (2020) The index insurance take-up puzzle: new experimental and quasiexperimental evidence from Burkina Faso. Unpublished Working Paper. Available at https://www. stjohns.edu/sites/default/files/uploads/The\%20index\%20insurance\%20take-up\%20puzzle\%20new\%20 experimental\%20and\%20\%281\%29.pdf.

Stoeffler Q, Carter M, Gelade W and Guirkinger C (2020) The Spillover Impact of index Insurance on Agricultural Investment by Cotton Farmers in Burkina Faso. NBER Working Paper No. 27564. Cambridge, MA: National Bureau of Economic Research.

Suarez P and Linnerooth-Bayer J (2010) Micro-insurance for local adaptation. Wiley Interdisciplinary Reviews: Climate Change 1, 271-278.

Tadesse MA, Alfnes F, Erenstein O and Holden ST (2017) Demand for a labor-based drought insurance scheme in Ethiopia: a stated choice experiment approach. Agricultural Economics 48, 501-511.

Takahashi K, Ikegami M, Sheahan M and Barrett CB (2016) Experimental evidence on the drivers of index-based livestock insurance demand in southern Ethiopia. World Development 78, 324-340.

Takahashi K, Barrett CB and Ikegami M (2019) Does index insurance crowd in or crowd out informal risk sharing? Evidence from rural Ethiopia. American Journal of Agricultural Economics 101, 672-691.

Trærup SLM (2012) Informal networks and resilience to climate change impacts: a collective approach to index insurance. Global Environmental Change 22, 255-267.

Vasilaky K, Diro R, Norton M, McCarney G and Osgood D (2019) Can education unlock scale? The demand impact of educational games on a large-scale unsubsidised index insurance programme in Ethiopia. Journal of Development Studies 56, 361-383.

Vincent K, Besson S, Cull T and Menzel C (2018) Sovereign insurance to incentivize the shift from disaster response to adaptation to climate change - African risk capacity's extreme climate facility. Climate and Development 59, 385-388.

Visser M, Jumare H and Brick K (2020) Risk preferences and poverty traps in the uptake of credit and insurance amongst small-scale farmers in South Africa. Journal of Economic Behavior \& Organization 180, 826-836.

Von Negenborn F, Weber R and Musshoff O (2018) Explaining weather-related credit risk with evapotranspiration and precipitation indices. Agricultural Finance Review 78, 246-261.

Vrieling A, Meroni M, Shee A, Mude AG, Woodard J, de Bie CAJMK and Rembold F (2014) Historical extension of operational NDVI products for livestock insurance in Kenya. International Journal of Applied Earth Observations and Geoinformation 28, 238-251.

Vrieling A, Meroni M, Mude AG, Chantarat S, Ummenhofer CC and de Bie KCAJM (2016) Early assessment of seasonal forage availability for mitigating the impact of drought on East African pastoralists. Remote Sensing of Environment 174, 44-55.

Wang HH, Karuaihe RN, Young DL and Zhang Y (2013) Farmers demand for weather-based crop insurance contracts: the case of maize in South Africa. Agrekon 52, 87-110.

Wasunna N and Frydrych J (2017) Person-to-government (P2G) Payment Digitisation: Lessons from Kenya. London: GMSA.

Weber R, Fecke W, Moeller I and Musshoff O (2015) Meso-level weather index insurance: overcoming low risk reduction potential of micro-level approaches. Agricultural Finance Review 75, 31-46.

Webster PJ (2013) Meteorology: improve weather forecasts for the developing world. Nature 493, 17-19.

World Bank (2015a) Achievements in ACP Countries by Global Index Insurance Facility Phase 1 (2010-2015). Washington, DC: The World Bank. 
World Bank (2015b) Kenya. Toward A National Crop and Livestock Insurance Program: Background Report. Washington, DC: The World Bank.

World Bank (2018) What People Want: Investigating Inclusive Insurance Demand in Ethiopia. Washington, DC: The World Bank.

World Bank (2019) Agriculture Finance Diagnostic - Zambia. Washington, DC: The World Bank.

Yilma Z, Mebratie A, Sparrow R, Abebaw D, Alemu G and Bedi AS (2017) Coping with shocks in rural Ethiopia. The Journal of Development Studies 50, 1009-1024.

Yuzva K, Wouter Botzen WJ, Brouwer R and Aerts JCJH (2018) A global review of the impact of basis risk on the functioning of and demand for index insurance. International Journal of Disaster Risk Reduction 28, $845-853$.

Cite this article: Nshakira-Rukundo E, Kamau JW, Baumüller H (2021). Determinants of uptake and strategies to improve agricultural insurance in Africa: a review. Environment and Development Economics 26, 605-631. https://doi.org/10.1017/S1355770X21000085 